\title{
Consumer Intention to Adopt Smartphone Apps: An Empirical Study of Pakistan
}

\author{
Shahida Parveen \\ Government College Women University, Faisalabad
}

\begin{abstract}
The paper investigates the relationship between the perceived usefulness, perceived ease of use, perceived enjoyment, social needs, subjective norms, self-efficacy and personal attitude with a mediating role of Intention to adopt smart phone apps and impact on the customer behavior. The current recognition of smart phones is a result of rapid development in smart phone apps that offer much kind of mobile persistent services. We used theory of planned behavior for consumer intention to adopt these apps. Our findings suggest that consumer intention is always based on these factors like perceived usefulness, perceived ease of use, perceived enjoyment, social needs, subjective norms, self-efficacy and personal attitude now a days and that intention to adopt apps will impact the consumer behavior
\end{abstract}

\section{Introduction}

In the digital era, market has recently experienced an exponential growth of mobile applications (apps), programs designed to perform a specific function on mobile computing devices (Kang, 2014). A recent national survey about the mobile app estimates that 185 billion apps have been downloaded by 2014 . Along this fame,Given that 46 percent of app users report having paid for their apps, that's big money, too. By 2017, its expected that over 268 billion downloads will generate $\$ 77$ billion worth of revenue (Clifford, 2014).Smartphone technology is a relatively new technology that is rapidly evolving and gradually impacting consumers' behavior, their daily activities, their social activities, the mobile industry, business activities, marketing, education, healthcare and more. Smartphone technology offers the potential as a means to improve efficiency, productivity, reduce cost, improve users' satisfactions and enhance their experience in a number of related industries including mobile industry, healthcare, financial, ecommerce, education, entertainment, tourism and more (Aldhaban, Daim, \& Harmon, 2015).

A smartphone is a mobile phone that offers an advanced functional system and links positively with a laptop computer. A mobile application (or mobile App) is software application that runs on a mobile device (smart phone, tablet, iPod, etc.), and has an operating system that supports standalone software (Wikipedia, 2012). Smart phones have several functions; e.g. media player, digital camera, global positioning system (GPS) steering unit, near field communication (NFC), and touch screen. Several educations and models of online buyer behavior have been achieved; however, there is no definite study of buying behavior of specific smartphone apps (Morimoto and Nagahata, 2013). However, we have appreciated increasing attention in mobile facilities in the crushed of information systems (IS) research (e.g. Zhou, 2014), most of them central idea on execution of smart phones apps. This reminders a problematic begging to be lectured on proceeded with use, and necessitates an inside and out intellectual capacity of the features influencing it (Ding and Chai, 2015). Behaviors are natural between a smartphone apps habit and the user. In this way, careful perception of constant use that is regularly based on cognition-oriented structures may be ridiculous in the context of mobile apps (Lin and Bhattacherjee, 2010). The estimating of International Data Corporation(IDC) is that mobile employees will be improved from just over one billion in 2010 to more than 1.3 billion by 2015 (IDC, 2012), and corporations greatly egg on personnel to "bring your own device" (BYOD) for both personal and commercial usage (Cousins and Robey, 2014). Our study proposes to explore how the facility gadget provided by Smartphone Apps would encourage customers' purpose to use of Apps (Hassan,Kouser, Shafqat, \&Azeem, 2014).

Smart phones apps have raise to be the main communication and service establishing process between the smartphone and the customer behavior with the approaching out of smart phones apps during the last decade. Apps offer several facilities and have an effect through their service practices on the normal lives of their customers (Dube, 2014). For example, Apple offers more than 750,000 apps to its customers via its smart phones apps Collection (Monti, 2013). Existing free versions of smart phones apps have typically replaced the use of new mobile-based services (Dube and Helkkula, 2015). To contract with this research break, the reason of this article is to examine customers' usage performance in the smartphone app background.In considering at consumer vision of learning that have put by scholar, as an adding lead of the technology acceptance model (TAM) by Davis (1989), the unified theory of acceptance and use of technology (UTAUT) was suggested by Venkateshet al. (2003). The UTAUT model's presentation in the area of awareness, presented now positively proves one area of MIS (Management Information System) study in which theory could be sustained through 
the application of smart phones. We are applied the theory of planned behavior of consumer that is linked to the use of smartphone apps as well as the value-based adoption theory and consumer planned behavior. The focal objective of my paper is to make out the causal factor customer behavior through denominating the goal to use the mobile phone apps to approve. For our research, we chosen a model that is Davis's Technology Acceptance Model (TAM) to which has been additional and distributed with the perceived usefulness, subjective norms, social influence, ease of use, social needs, and self-efficacy as well as personal attitude that influence the consumer intention towards smart phones' apps. The main objective of this study is to evaluate that the independent variable how affect to a customer and how do they divert intention to adopt smartphone apps and is there any influence on their behavior regarding adoption. Followings are some of the objective of the research

1. To understand how Perceived Usefulness influences on intention to adopt Apps.

2. To understand the effect of ease of use on intention to adopt Apps.

3. To understand the impact of Enjoyment on intention to adopt Apps.

4. To understand Social Needs has positively related with intention to adopt Apps.

5. To understand Social Influence has positively related with intention to adopt Apps.

6. To understand Subjective Norms have position related with intention to adopt Apps.

7. To understand Self-efficacy has influence on intention to adopt Apps?

8. To understand that Personal Attitude has related with intention to adopt apps.

9. To understand the mediating impact of Intention to Smartphone Adopt Apps between consumer behavior and PU, PEU, PE, PN, SI, PN, SE, PA?

\section{Literature Review}

The vital role of smart phone applications that companies offers a new kinds of products for consumer choice. A smart phone app is beneficial through immediate contact, making it a significant marketing instrument for the strength connection with consumers, regardless of providing information (Jin, 2015). In this study, psychology research exhibited the importance of smartphones in such a way that if psychology had no procedural apathy than how we would be able to assemble the behavioral data, the writers identified that we would use smartphone for this determination because they are universal, sense rich, computationally authoritative and remotely manageable. Smartphones has the imaginable to assemble very accurate and objective information from the millions of people about their activities and understandings without asking them to come in the organized labs. (Dufau et al., 2011; Kwok, 2009; Rachuri, \&Mascolo, 2011; Raento et al., 2009).Smartphone Apps is a comparative new business communication media, but the quick-tempered growth of this handheld device is often debated in recent studies (Lee \& Raghu, 2011). Linked with old-fashioned physical store businesses, mobile frequencies offer customers sufficiently of unique value, such as no timebased and longitudinal limitation, and accessibility of information. These Smartphone structures bring us different stages of suitability, and this device has arose as an important statement tool in our lives. Concerning the rapid extension of smartphone apps service, m-commerce is estimated to be the next trend of Internet business after e-commerce (Liang \& Wei, 2004).

According to Accenture (2012), people today adopt there should be an app for the whole thing. In other words, everything must be "amplified". As Wagner (2011, p. 28) states: "while the international smartphone market is developing speedily, little is known about how buyers make use of smartphones". There is a need for sellers to recognize the purchaser behavior for smartphone apps and recognize how and why they are used, in order to know how to best grasp out to clients through apps, as marketing networks, or as goods or facilities in themselves.Although, many smartphone apps give the impression to be developed without attentions to why and how people would want to use them. Therefore, without knowing the consumer professed charge in using the apps. Chen and Mort (2007) claim that when a technology, such as an app, is deliberate to use, perceived value has optimistic effect on technology eagerness. This means that for a person to practice an app, it should has usefulness, easiness of use, enjoyment and social needs.A common vision has been to look at value as characteristic in the product or facility at the time of discussion. On the other hand, several researchers (e.g. Normann and Ramírez, 1993; Vargo and Lusch, 2004; Edvardsson, Gustafsson and Roos, 2005;Vargo, Maglio and Akaka, 2008; Grönroos, 2008) claim that value is produced during usage, so called value-in-use. Valueinuse is based on consumption, in compare to value-in exchange that is based on trade (Vargo, Lusch and Morgan, 2006). Grönroos (2008) and Vargo, Maglio and Akaka (2008) argue that without value-in use, there is no valuein-exchange. Relating this to smartphone apps, value-in-exchange arises when the app is downloaded; however value-in-use emerges when the app is used. If the user of the app doesn't approve an app, there will be no value in having downloaded the app, so, no value-in-exchange.

\section{Technology Acceptance Model (TAM)}

As suggested in TAM, subjective norm, one of the social influence variables, refers to the perceived social pressure to perform or not to perform behavior (Ajzen, 1991). It seem important to determine how social 
influences affect the commitment of the customer toward use of theinformation system for understanding, explaining, and predicting system usage and acceptancebehavior(Malhotra \&Galletta, 1999). According to the study done by Gradon, Alshare, and Kwa (2005), subjective norm was originated to be a significant factor in affecting university students' intention to use smartphone apps. In contrast, the study done by Ndubisi (2006) showed that subjective norm had no significant effect on customers' intention to adopt smartphone apps.

\section{Unified Theory of Acceptance and Use of Technology (UTAUT)}

In the context of technology adoption, the logical action and planned behavior approach resulted in numeroustheories (The Diffusion of Innovation (DOI), Technology Acceptance Model (TAM), The Technology-Organization-Environment Framework (TOE), Institutional Theory, Resource-based Theory), of which the most frequently studied in educational settings is the Technology Acceptance Model (TAM; Davis, 1989), with two extended versions TAM2 (Venkatesh\& Davis, 2000) and TAM3 (Venkatesh\&Bala, 2008). Venkatesh and his colleagues (2003) formulate their Unified Theory of Acceptance and Use of Technology (UTAUT) as a synthesis of its predecessors and describe technology use under the influence of use intention, further determined by performance expectancy, effort expectancy, and social influence.

\section{Ajzen's Theory of Planned Behavior}

This study used IcekAjzen's Theory of Planned Behavior to research public relations faculty intentions to adopt apps. All of the main predictor variables (Subjective Norms, Attitude toward the Act and Perceived Behavioral Control) were statistically significant at changing grades in solving intent to adopt smartphones apps. Of the three, Subjective Norms was originated to be the strongest predictor of Intention to adopt apps (Knabe, 2012). Intention is the indicator of an individual's readiness to perform a given behavior (Ajzen\&Fishbein, 1975). The theory of planned behavior (TPB) (Ajzen\&Fishbein, 1975) indicates the relationship between attitude, intention and behavior, in which intention is considered as the immediate factor in explaining consumers' behavior. Ajzen (1991) advocates that only the level of specific beliefs, but not the generic operation across applications that we can learn about critical factors inducing one person to engage in the behavior of interest. Based on this approach, this study identify the protruding belief of Smartphone apps users.

\section{Research Model}

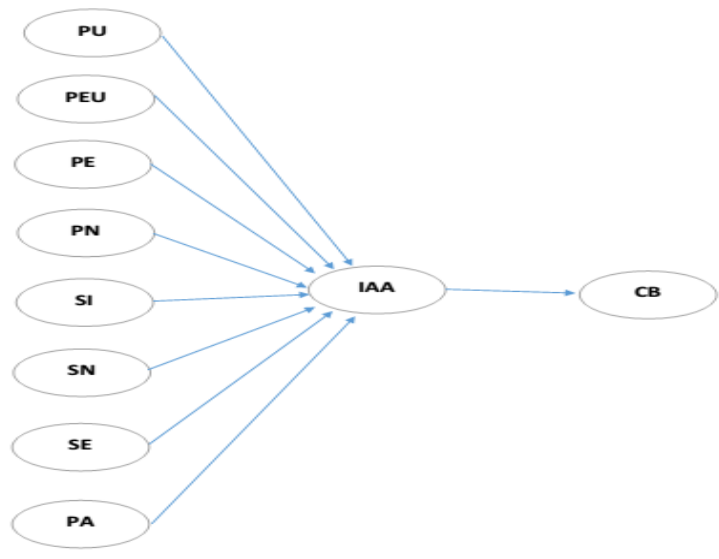

Variables and Proxies

\begin{tabular}{|l|l|l|}
\hline Variable & Proxy & Variable Name \\
\hline Independent Variable & PU & Perceived Usefulness \\
& PEU & Perceived Ease of Use \\
& PE & Perceived Enjoyment \\
& PN & Personal Need \\
& SI & Social Influence \\
& SN & Subjective Norms \\
& SE & Self-Efficacy \\
& PA & Personal Attitude \\
\hline Mediating Variable & IAA & Intention to Adopt Apps (Smartphone Apps) \\
\hline Dependent Variable & CB & Customer Behavior \\
\hline
\end{tabular}

In this study, variable have their proxies that are the representative of them. PU shows Perceived Usefulness, PEU means Perceived Ease of Use, PE denotes that Perceived Enjoyment, PN stands for Personal Need, SI is Social Influence, SN means Subjective Norms, SE shows Self-Efficacy and PA denotes Personal 
Attitude, these are the independent variables in this paper. IAA is a mediating variable that shows Intention to Adopt Apps (Smartphone Apps) and CB is dependent variable that is customer behavior. The model of this study shows that there is direct relationship between independent variable and mediator and other relationship between mediator and dependent variable in this paper.

\section{Hypothesis Development \\ Perceived Usefulness}

Customer satisfaction is typically distinct as a support intake reaction and result concerning a definite product or service.Oliver (1980) stated that customer fulfillment is the outcome of an evaluative procedurethat differences the pre-purchase prospect with perceived performance during and after the consumption experience. As numerous researchers have decided (Jung and Lee, 1995; Oliver, 1997;Cronin et al., 2000; Yang et al., 2005), customer's satisfaction on a service has long been documented as a critical idea that positively rises customer loyalty and influences continuance purpose. Perceived usefulness (PU) is one of the densest beneficial component in the study to technologyacceptance, well-defined as degree to which clients trust to improve job performance by using definite organization or technology (Davis, 1989). Applying his definition in the situation of apps adoption, PU represents to "how Smartphone users and consumers use apps based store".

\section{H1 PU has positively influences on intention to adopt apps. \\ Perceived Ease of Use}

Perceived ease of use is vital for the machinists to increase the smartphone user's satisfaction and intentions to have using the service (continuance intention) and differentformer studies on user's behavior have definite and established the continuance intent is an vital factor to encourage the users to keep by the service (Davis, 1989; Venkatesh et al., 2003; Lee et al., 2005). PEU denotes to "individuals' believe that using a specific product/service would be free from exertion" (Davis, 1989). Applying the same idea in the framework of Apps technology, PEU is interpreted as the extent to which users perceive the ease of interaction with Apps allows them to obtain proper and useful information they want.As smartphone diffusion increases each year, service quality has develop a serious anxiety for the service providers. It is not solid to catch user complaints regarding call quality for certain budget smartphones and wireless network services.

\section{H2 PEU has positively effect on intention to adopt apps. \\ Perceived Enjoyment}

Part shopping highlights looking for other to effectively locate the precise blessings (Arnold and Reynolds, 2003). Customers play their character in the process of shopping to discover the accurateaidsproducts for other people (Tauber, 1972) while filling their internalneeds for role playing (McGiure, 1974). While applying part shopping to the portable shopping system, the individual property of the cell phone bears customers a substantial shrewdness of proprietorship demonstrating the individual's part in imparting data and insights in the versatile shopping channels (Jones and Issroff, 2007). In addition, an on-the-go individual device of mobile phone certificates customers to achieve productinformation anytime and anyplace, improving a person's role to catch out the right product at the right time.Perceived enjoyment, "The extent to which the activity of using a specific system is perceived to be enjoyable in its own right, aside from any performance consequences resulting from system use." By definition, perceived enjoyment (PE) is the intrinsic all-inclusive sensation gaining from the total participation of the task, can be viewed as a non-apparent cause that influences user to do an activity.

\section{H3 PE has positively effect on intention to adopt apps. Social Needs}

All three important perspectives, namely perceived usefulness, sybaritic, and social aspects, significantly influenced users' satisfaction with and custom of using smartphone's Apps. After examination carefully, it was found that perceived enjoyment had a dominant impact on satisfaction and usual usage among all three decades. These findings demonstrate that users are much more alarmedwith whether the use of a smart phones' app can fulfill their enjoyabletouch, functional advantage, and social need to connect with friends (Hsiao, et., all, 2015).Abraham Maslow developed five stages of wants that motivate human behavior. The five stages in Maslow's hierarchy of needs in order from lowest to highest level include physiological, safety, social (love and belonging), esteem, and self-actualization. Smartphones apps has dynamic changed the way of people lives, shops, purchases, plays and connect with world (Goldman. 2010). Social needs include love, affection and belongingness (Schiffman et al., 2009). Smart phones demonstrates larger and higher resolution curtains and deliver consumers with a marvelous display of features, including mobile web browsing, a lot of applications, e-mails, instant messaging, picture messaging, video and audio playbacks, GPS, different games, a video camera, picture and video editing and much more (Goldman, 2010). 


\section{H4 Social Needs has positively related with intention to adopt apps. Social Influence}

"Social influences means one person causes in another to make a change on his/her feelings, attitudes, thoughts and social behavior, intentionally or unintentionally" (Rashotte, 2007). Social influence is the result of socialization process which a person undergoes throughout whole of his life. A person is influenced by his/her family, friends, colleges, movies, media etc. "Social Influence is defined as the degree to which an individual perceives that important others believe he or she should use the new system" (Venkatesh, 2002).Social shopping focuses on the aspect of social influences of important others and interpersonal relationships with others during a shopping trip (Arnold and Reynolds, 2003; Kim, 2006). Social interaction, reference group affiliation, and communicating with others are related to social shopping motivation (Rohm and Swaminathan, 2004).Since consumers consider shopping as an opportunity to socialize with others (Cardoso and Pinto, 2010) through communications and social interaction in shopping context (Guido, 2006), the social shopping motivation further affect choosing a shopping channel (Albaet al., 1997).

\section{H5 Social Influence has positively related with intention to adopt apps. Subjective Norms}

Technology use research often focuses on the antecedents associated with intention to use a specific technology, or the actual use of such technology. Theories developed toexplain this phenomenon include the technology acceptance model (Davis, 1989), the theory of reasoned of action (Ajzen and Fishbein, 1980; Fishbein and Ajzen, 1975), the theory of planned behavior (Ajzen, 1991). More recent efforts reflect an attempt to apply these theories in an m-commerce setting. For example, Rao and Troshani (2007) develop a model of adoption intentions based on perceived usefulness and perceived ease of use, along with user predisposition and social influence. Maity (2010) extracts TAM-related factors, i.e. perceived usefulness and ease of use, as well as subjective norms, behavioral controls, self-efficacy and the role of alternate channels, from qualitative data on m-commerce usage. Khalifa and Shen (2008) apply the theory of planned behavior - an extension of the theory of reasoned action - to develop an m-commerce framework, with adoption as the behavioral outcome predicted by perceived consequences of adoption, attitude and subjective norms. These studies, though, examine the antecedents of technology use without considering how respondents expect the technology to perform specifically.A broad definition of perceived or subjective norm is "the perceived social pressure to perform or not to perform the behavior" in question (Ajzen, 1991, p. 188).

\section{H6 Subjective Norms have position related with intention to adopt apps. Self-Efficacy}

In the field of information systems, an examination of recent studies reveals that researchers have mostly focused on only two types of emotions when examining experience with information technologies: anxiety (Brownet al., 2004) and perceived enjoyment (Koufaris, 2002). IT-related anxiety is posited as a major inhibitor of use intentions. However, with increasing prevalence of information technologies, the influence of anxiety may not be as prominent. Moreover, the impact of anxiety is limited to the initial stage because one major source of anxiety is perceptions of low self-efficacy, which will improve as more experience is accumulated through repeated use (Agarwalet al., 2000). Perceived enjoyment is one aspect of positive emotion. It is intended to capture the hedonic benefits of IT use. These two types of emotions only give a relatively narrow account of emotions in IT use. The emotions experienced during the course of IT usage are far richer than just anxiety and enjoyment. A more comprehensive investigation of emotions arising from IT use and their relationships with cognition and intentions is required. Self-efficacy refers to an individual's belief in his or her capacity to execute behaviors necessary to produce specific performance attainments (Bandura, 1977, 1986, 1997). Self-efficacy reflects confidence in the ability to exert control over one's own motivation, behavior, and social environment.

\section{H7 Self-efficacy have positively influence on intention to adopt apps. Personal Attitude}

In general, forced use of educational technology should be avoided (Liu, 2012), no matter what the profession of the learners is. Notably, technology use may implicitly become compulsory, if there is no alternative in using technology in order to reach an educational goal. Forced technology use contradicts personal attitudes and intentions, and may thus increase computer anxiety and impair learning motivation (Deci\& Ryan, 2000). Therefore, learning environments should be provided along with technology-free alternatives, or at least include face-to-face components.A tendency to respond positively or negatively towards a certain idea, object, person, or situation. Attitude influences an individual's choice of action, and responses to challenges, incentives, and rewards (together called stimuli). 


\section{H8 Personal Attitude has positively related with intention to adopt apps. Adoption Intention \& Theory of Planned Behavior}

Intention is the indicator of an individual's readiness to perform a given behavior (Ajzen\&Fishbein, 1975). Intention is determined by the individual's attitude toward the technology and whether they are willing to take a specific action if it is perceived to lead positive outcomes (Compeau\& Higgins, 1995). The theory of planned behavior (TPB) indicates the relationship between attitude, intention and behavior, in which intention is considered as the immediate factor in explaining consumers' behavior. Intention is determined by the individual's attitude toward the technology and whether they are willing to take a specific action if it is perceived to lead positive outcomes. A common view has been to look at value as inherent in the product or service at the time of exchange. However, several scholars (e.g. Normann and Ramírez, 1993; Vargo and Lusch, 2004; Edvardsson et al., 2005; Vargo et al., 2008; Grönroos, 2008) argue that value is created during usage, so called value-in-use. Valuein-use is based on consumption, in contrast to value-in-exchange that is based on trade (Vargo et al., 2006). Grönroos (2008) and Vargo et al., (2008) argue that without value-in use, there is no value-in-exchange. Applying this to smartphone apps, value-in-exchange emerges when the app is downloaded, whereas value-in-use emerges when the app is used. If the user of the app doesn't adopt an app, there will be no value in having downloaded the app, thus, no value-in-exchange.

H9 Intention to adopt apps mediates the relationship between consumer behavior and PU, PEU, PE, PN, SI, SN, SE and PA.

\section{Research Methodology}

\section{Research Design}

The study was conducted to find the impact of Perceived Usefulness, Perceived Ease of Use, Perceived Enjoyment, Personal Needs, Social Influence, Subjective Norms, Self-Efficacy, Personal Attitude on Intention to Adopt Smartphone Apps and the mediating impact of Intention to Adopt Apps between PU, PEU, PE, PN, SI, SE, PA and Customer Behavior. The method was adopted that is online questionnaire in Google Drive. Data was collect at once the period of almost 5 Weeks (From January 2, 2016 to February 8 2016) from different people in the Pakistan who are using Smartphone's Apps.

\section{Sample and Data Collection Procedures}

Each questionnaire consists of two sections. Section-1 was about the basic information like name, city, gender and education.Section-2 was about the questions of independent variables like independent variable (Perceived Usefulness, Perceived Ease of Use, Perceived Enjoyment, Personal Needs, Social Influence, Subjective Norms, Self-Efficacy and Personal Attitude) with the mediating impact of Intention to Adopt Apps as well as dependent variable (customer behavior).The procedure adopted for sample calculation resulted in minimum sample size. However, in this study, questionnaire was sent to their email address to 220 persons in the different cities in Pakistan like Faisalabad, Multan, Jhang, Bhakkar and Haiderabad. Out of 310, only 305 respondents filled the questionnaire and 6 responses are incomplete, remaining is fully completed. In total responses, out 299 responses 227 are male and 72 are female respondents.

\section{Measures}

In my study, five likert scale was adopted to get the response about independent variable (Perceived Usefulness, Perceived Ease of Use, Perceived Enjoyment, Personal Needs, Social Influence, Subjective Norms, Self-Efficacy and Personal Attitude) with the mediating impact of Intention to Adopt Apps as well as dependent variable (customer behavior). Range of this likert scale was as 1 for strongly disagree, 2 for disagree, 3 for neutral, 4 for agree $\& 5$ for strongly agree. The approach was use deductive approach for sample in my study. The software which is used for analysis was PLS (Partial Least Square) and an area of sampling was different cities of Pakistan.

Descriptive Statistics \& Frequencies Analysis

\section{Data Analysis \& Results}

In my study, statistical analysis was used to find the missing values in date collected of each question. Descriptive analysis was as under:

\section{Gender wise Responded}

Out of total 299 respondents $(75.96 \%)$ were male \& $24.04 \%)$ were female in the study samples.

Age wise Respondents

Out of total 299 respondents, 105 persons were of age 20-25 year, 70 were between 25-30year, 50 respondents were between 30-35 years, 40 respondents were between 35-40 years and 34 were between above 40 . 


\section{Education wise respondents}

Out of 299 total respondents (51.92\%) were of education up to Bachelor level, (24\%) were of Master level, $(14.42 \%)$ were M.Phil. \&(9.66\%) were others (i.e. CA, PIPFA etc.) in my study.

\section{Finding and Analysis}

\section{Reflective Measurement Model}

This measurement model is evaluated with respect to reliability and validity. The reliability was assessed by Cronbach's alpha which is a traditional measure of internal consistency. All constructs revealed acceptable levels of Cronbach's alpha, ranging from 0.615 to 0.810 Further, composite reliability is also used to assess internal consistency argued: "Cronbach's alpha tends to provide a severe underestimation of the internal consistency reliability of latent variables in PLS path models".

The composite reliability results also indicated that the measures are robust in terms of internal consistency reliability. The indexes of composite reliability showed satisfactory level, ranging from 0.753 to 0.865 which are nearer to 0.8

Table

\begin{tabular}{|l|c|c|}
\hline \multicolumn{1}{|c|}{ Variables } & $\begin{array}{c}\text { Composite } \\
\text { Reliability }\end{array}$ & Cronbachs Alpha \\
\hline Customer Behavior & 0.818 & 0.560 \\
\hline Intention to Adopt Apps & 0.857 & 0.789 \\
\hline Perceived Ease of Use & 0.834 & 0.756 \\
\hline Perceived Enjoyment & 0.770 & 0.568 \\
\hline Perceived Usefulness & 0.865 & 0.810 \\
\hline Personal Attitude & 0.792 & 0.698 \\
\hline Personal Needs & 0.799 & 0.662 \\
\hline Self-Efficacy & 0.824 & 0.720 \\
\hline Social Influence & 0.753 & 0.516 \\
\hline Subjective Norms & 0.786 & 0.612 \\
\hline
\end{tabular}

\section{Coefficient of Determination (R2)}

$\mathrm{R} 2$ is a measure of predictive accuracy and its magnitude describes a combined effect of exogenous latent variables on each endogenous variable (Hair et al. 2014). In PLS-SEM, R2 value is the most commonly used criterion to describe the predictive accuracy of the model (Hair et al. 2014). The value of R2 ranges from 0 to 1 and higher value indicates greater predictive accuracy (Hair et al. 2014). As such, R2 values of 0.25, 0.50, and 0.75 are interpreted as weak, moderate and substantial respectively (Hair et al. 2011; Hair et al. 2014). In this study, the independent variable (PEU, PU, PE, SN, SE, PA, PI, PN) explain $97.8 \%$ to mediating variable that is Intention to Adopt Smartphone apps and it is substantial but mediator (Intention to Adopt Smartphone Apps) explained $19.2 \%$ to dependent variable (Customer behavior) that is weak.

Table R2

\begin{tabular}{|l|c|}
\hline \multicolumn{1}{|c|}{ Variable } & R Square \\
\hline Customer Behavior & 0.19 .2 \\
\hline Intention to Adopt Apps & 0.978 \\
\hline
\end{tabular}

\section{Beta-Coefficient and Average Variance Extracted}

Beta coefficient is the measure of results that shows how much time change in one variable leads to another variable and AVE is a measure of validity which must be higher than 0.50 . In this study, if one unit change in independent variables (PEU, PE, PU, PA, PN, SE, SI, SN), there will be $-0.044,-0.018,0.017,0.034$, $-0.019,0.677,-0.043$ and 0.443 unit change in intention to adopt apps respectively as well as if one unit change in intention to adopt apps, there will be 0.438 unit change in customer behavior. If we discuss the results of AVE that show significant because the value of AVE is more than 0.50 


\begin{tabular}{|l|c|c|}
\hline \multicolumn{1}{|c|}{ Variables } & AVE & Beta \\
\hline Customer Behavior & 0.693 & -------- \\
\hline Intention to Adopt Apps & 0.548 & 0.438 \\
\hline Perceived Ease of Use & 0.502 & -0.044 \\
\hline Perceived Enjoyment & 0.534 & -0.018 \\
\hline Perceived Usefulness & 0.562 & 0.017 \\
\hline Personal Attitude & 0.560 & 0.034 \\
\hline Personal Needs & 0.574 & -0.019 \\
\hline Self-Efficacy & 0.546 & 0.677 \\
\hline Social Influence & 0.623 & -0.043 \\
\hline Subjective Norms & 0.562 & 0.443 \\
\hline
\end{tabular}

\section{Latent Variable Correlations}

As the study aims to find the check the impact independent variable (Perceived Usefulness, Perceived Ease of Use, Perceived Enjoyment, Personal Needs, Social Influence, Subjective Norms, Self-Efficacy and Personal Attitude) with the mediating impact of Intention to Adopt Apps as well as dependent variable (customer behavior). In order the test the relationship among the variables we conducted correlation analysis as shown in table below. Each latent variable shows the correlation with one another in given table.

\begin{tabular}{|l|l|l|l|l|l|l|l|l|l|l|}
\hline Variable & CB & IAA & PEU & PE & PU & PA & PN & SE & SI & SN \\
\hline $\begin{array}{l}\text { Customer } \\
\text { Behavior }\end{array}$ & 1.000 & & & & & & & & & \\
\hline $\begin{array}{l}\text { Intention to Adopt } \\
\text { Apps }\end{array}$ & 0.438 & 1.000 & & & & & & & & \\
\hline $\begin{array}{l}\text { Perceived Ease of } \\
\text { Use }\end{array}$ & 0.484 & 0.288 & 1.000 & & & & & & & \\
\hline $\begin{array}{l}\text { Perceived } \\
\text { Enjoyment }\end{array}$ & 0.287 & 0.212 & 0.256 & 1.000 & & & & & & \\
\hline $\begin{array}{l}\text { Perceived } \\
\text { Usefulness }\end{array}$ & 0.401 & 0.362 & 0.433 & 0.435 & 1.000 & & & & & \\
\hline Personal Attitude & 0.275 & 0.269 & 0.396 & 0.403 & 0.443 & 1.000 & & & & \\
\hline Personal Needs & 0.337 & 0.200 & 0.213 & 0.508 & 0.328 & 0.218 & 1.000 & & & \\
\hline Self-Efficacy & 0.573 & 0.920 & 0.371 & 0.266 & 0.379 & 0.287 & 0.253 & 1.000 & & \\
\hline Social Influence & 0.331 & 0.264 & 0.336 & 0.438 & 0.478 & 0.789 & 0.254 & 0.305 & 1.000 & \\
\hline Subjective Norms & 0.339 & 0.838 & 0.186 & 0.152 & 0.286 & 0.215 & 0.143 & 0.598 & 0.209 & 1.000 \\
\hline
\end{tabular}

**. Correlation is significant at the 0.05 level (2-tailed).

\section{PLS-SEM Model}

After calculation of all latent variable, different cross loading are attached its variable in given graphical representation below:

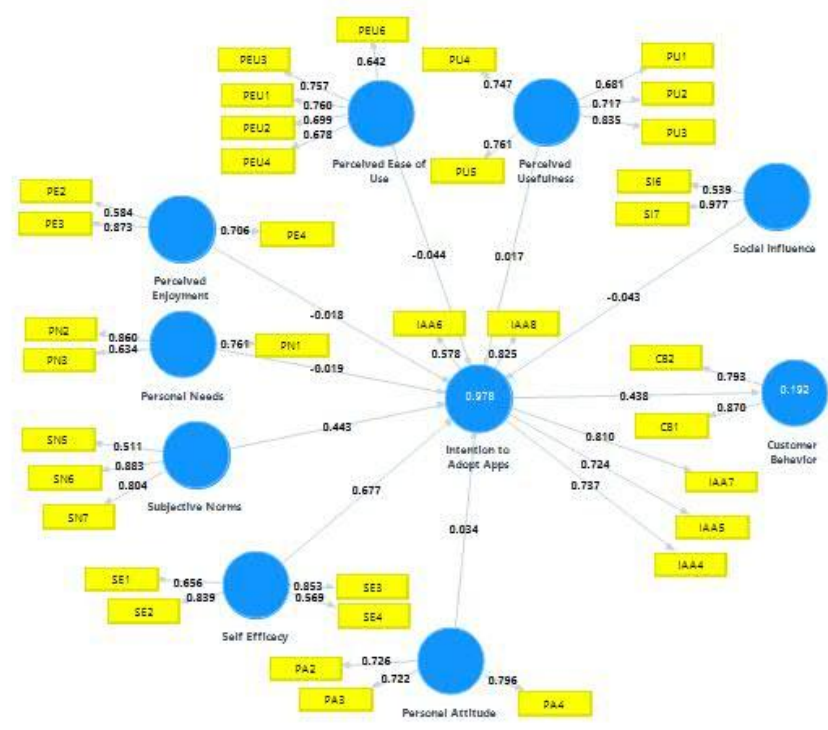




\section{Discussion}

The present study's aim to investigate the two relationship between model that are the relationship of independent variable (perceived usefulness, perceived ease of use, perceived enjoyment, personal need, subjective norms, personal attitude and social influence) with intention to adopt smartphone apps as a mediator and other relationship between intention to adopt apps and customer behavior. In previous studies, we determined that there is weak relationship of independent variables with intention to adopt apps but in current study, we include 4 other variables that have significant relation with intention to adopt apps and other variable is customer behavior on the basis of theory of planned behavior which is explained above. Accordance to this study, all independent variable like perceived usefulness, perceived ease of use, perceived enjoyment, personal need, subjective norms, personal attitude and social influence have a significant relationship with intention to adopt apps and there is direct relationship between intention to adopt apps and customer behavior, the results showed that the independent variable explained the mediator (Intention to Adopt Apps) that is measured by R2, here is strong relationship between independent variables and mediating variable but due to technology and behavior of the people there is weak relationship between mediator (intention to adopt smartphone apps) and dependent variable (customer behavior).

In this study, we develop a mediating variable that intention to adopt apps and we determine the effect of this variable between independent variables and dependent variable through coefficient of determination, the results show that there is an influence of mediator in this research because the coefficient of determination is changed in inner and outer model so there is great role of intention to adopt apps between (perceived usefulness, perceived ease of use, perceived enjoyment, personal need, subjective norms, personal attitude and social influence) and customer behavior also known as full mediation in this research.

\section{Practical implications \& Limitations}

There is open door for future exploration to extend the example estimate and examine in distinctive land zones in Pakistan with a specific end goal to upgrade the comprehension in regards to usage of cell phone applications. The R-squared for this study was low, (as talked about prior the target of scientists was not to figure a model, rather to research the peripheral impacts of chose logical variables), inferring there are extra components that effect interest for cell phone to be investigated further, variables, for example, lifestyle, culture, and demographics, for example, gender or age, and so forth. Moreover, it is important to research contrasts in item request among cell phone clients and essential portable telephone clients. The limitation of this study was limited area of coverage, that leads to scarcity of data and this may not reliable and valid results. When we conducted research in developed cities of Pakistan like (Lahore, Karachi, Islamabad), the perception of people is totally changed so, and any organization can't rely on this data for any decision. Other limitation of my study is that today's view of people of different cities varies so no exact answer may be given.

\section{Reference}

[1]. (Dufau et al., 2011; Kwok, 2009; Rachuri\&Mascolo, 2011; Raento, Oulasvirta, \& Eagle, 2009)

[2]. (Normann and Ramírez, (1993); Vargo and Lusch, 2004; Edvardsson, Gustafsson and Roos, 2005;Vargo, Maglio and Akaka, 2008; Grönroos, 2008)

[3]. (Vargo, Lusch and Morgan, (2006). Grönroos (2008) and Vargo, Maglio and Akaka (2008)

[4]. A Communications Perspective," Proceedings of the CHI 2010: Perspectives on Design Conference, Atlanta, GA, April 10-15, 2247-2256. Tsang, Melody M., Shu-Chun Ho, and Ting-Peng Liang (2004), "Consumer Attitudes toward Mobile Advertising: An Empirical Study,” International Journal of Electronic Commerce, 8, 3, 65-78.

[5]. Agarwal, R., Sambamurthy, V. and Stair, R.M. (2000),"Research report: the evolving relationship between general and specific computer self-efficacy - an empirical assessment", Information Systems Research, Vol. 11 No. 4, pp. 418-430.

[6]. Ajzen, I. (1991). The theory of planned behavior. Organizational Behavior and Human Decision Processes, 50,179-211.

[7]. Ajzen, I. and Fishbein, M. (1980),Understanding Attitudes and Predicting Social Behavior,

[8]. Alba, J., Lynch, J., Weitz, B., Janiszewski, C., Lutz, R. and Wood, S. (1997), "Interactive home shopping: consumer, retailer, and manufacturer incentives to participate in electronic marketplaces",Journal of Marketing, Vol. 61 No. 3, pp. 38-53.

[9]. Ann Peru Knabe, B.A, M.A., APR (2012). Applying Ajzen's Theory of Planned Behavior to a Study of online Course Adoption in Public Relations Education.

[10]. Arnold, M.J. and Reynolds, K.E. (2003), "Hedonic shopping motivations”,Journal of Retailing,

[11]. Brown, S.A., Fuller, R.M. and Vician, C. (2004),"Who's afraid of the virtual world? Anxiety and computer-mediated communication", Journal of the Association for Information Systems, Vol. 5 No. 2, pp. 79-107.

[12]. Cardoso, P.R. and Pinto, S.C. (2010), "Hedonic and utilitarian shopping motivations among Portuguese young adult consumers", International Journal of Retail \& Distribution Management, Vol. 38 No. 7, pp. 538-58.

[13]. Chen, C. H. and Mort, G. S. (2007). Consumers technology adoption behavior: an alternative model. The Marketing Review, 7(4), 355-368.

[14]. Chun-Hua Hsiao, Jung-Jung Chang, Kai-Yu Tang, (2015), "Exploring the influential factors in continuance usage of mobile social Apps: Satisfaction, habit, and customer value perspectives", Department of Marketing, Kainan University, No. 1 Kainan Road, Luchu, Taoyuan County 33857, Taiwan.

[15]. consumers ready? Marketing Intelligence \& Planning, 30(4), 418-443.

[16]. Cronin, J., Brady, M., Hult, G., (2000). Assessing the effects of quality, value, and customer satisfaction on behavior intentions in service environments. J. Retail. 76 (2), 193-218. 
[17]. Davis, F. (1989). Perceived usefulness, perceived ease of use, and user acceptance of information technology. MIS Quarterly, 13, 319-340.

[18]. Davis, F., (1989). Perceived usefulness, perceived ease of use, and user acceptance of information technology. MIS Q. 13 (3), $319-$ 340 .

[19]. Deci, E. L. \& Ryan, R. M. (2000). The „what?“ and „why?“ of goal pursuits: Human needs and the selfdetermination of behavior. Psychological Inquiry, 11(4), 227-268.

[20]. Edvardsson, B., Gustafsson, A. and Roos, I. (2005). Service portraits in service research: a critical review. International Journal of Service Industry Management, 16(1), 107-121.

[21]. Fishbein, M. and Ajzen, I. (1975),Belief, Attitude, Intention, and Behavior: An Introduction to

[22]. Gartner, 2012. http://www.gartner.com/newsroom/id/2153215

[23]. Goldman, S. M. (2010). Transformers. Journal of Consumer Marketing, 27(5), 469-73

[24]. Grandon, E., Alshare, O., \& Kwan, O. (2005). Factors influencing student intention toadopt online classes: A cross-cultural study. Journal of Computing Sciences in Colleges, 20(4), 46-56.

[25]. Grönroos, C. (2008). Service logic revisited: who creates value? And who co-creates? European Business Review, 20(4), 298314.

[26]. Gupta, S., 2013. For mobile devices, think Apps, not ads. Harvard Business Review 91, 70-75.

[27]. Jones, A. and Issroff, K. (2007), "Motivation and mobile devices: exploring the role of appropriation and coping strategies",Research in Learning Technology, Vol. 15 No. 3, pp. 247-528, available at: http://oro.open.ac.uk/10278/ (accessed 9 November 2010).

[28]. Journal of Marketing, 68(1), 1-17.

[29]. Jung, K.E., Lee, D.M., 1995. Reciprocal effect of the factors influencing the satisfaction of is users. Asia Pac. J. Inform. Syst. 5 (2), 199-226.

[30]. Khalifa, M. and Shen, K.N. (2008), "Drivers for transactional B2C m-commerce adoption: extended theory of planned behavior",Journal of Computer Information Systems, Vol. 48 No. 3, pp. 111-117.

[31]. Kim, H.S. (2006), "Using hedonic and utilitarian shopping motivations to profile inner city consumers",Journal of Shopping Center Research, Vol. 13 No. 1, pp. 58-79.

[32]. Koufaris, M. (2002), “Applying the technology acceptance model and flow theory to online consumer behavior”, Information Systems Research, Vol. 13 No. 2, pp. 205-223.

[33]. Lee, G.G., Lin, H.F., (2005). Customer perceptions of e-service quality in online shopping. Int. J. Retail Distribution Manage. 33 (2), 161-176.

[34]. Lee, Y.K., Lee, J.R., Yoo, D., (2005). The structural relationships between interactivity, identification, relationship quality, and loyalty of e-brand in internet site. Asia Pac. J. Inform. Syst. 15 (4), 1-26.

[35]. Liu, S. (2012). The impact of forced use on customer adoption of self-service technologies. Computers in Human Behavior, 28(4), 1194-1201.

[36]. Maity, M. (2010), "Critical factors of consumer decision-making on m-commerce: a qualitative studyin the united states", International Journal of Mobile Marketing, Vol.5, No.2,pp.87-101.

[37]. Malhotra, Y., \&Galletta, D. F. (1999).Extending the technology acceptance model to account for social influence: Theoretical bases and empirical validation. Proceedings of the 32nd Hawaii InternationalConference on System Sciences, 1999.

[38]. Markets and markets, (2010), http://www.marketsandmarkets.com/PressReleases/mobile-applications-market.asp In-Stat (2011)

[39]. McGuire, W.J. (1974), "Psychological motives and communication gratification", in Blumler, J.G. and Katz, E. (Eds), The Uses of Mass Communications, Sage Publications, Beverly Hills, CA

[40]. Ndubisi, N. O. (2006). Factors of online learning adoption: A comparative juxtaposition of the theory of planned behavior and the technology acceptance model. International Journal on E-Learning, 5(4), 571-591.

[41]. Normann, R. and Ramírez, R. (1993). From Value Chain to Value Constellation: Designing Interactive Strategy. Harvard Business Review, 71(4), 65-77.

[42]. Oliver, R.L., (1980). A cognitive model of the antecedents and consequences of satisfaction decisions. J. Marketing Res. 17, 460469.

[43]. Oliver, R.L., 1 (997). Satisfaction: A Behavioral Perspective on the Consumer. McGraw-Hill, New York.

[44]. Persaud, A. and Azhar, I. (2012). Innovative mobile marketing via Smartphones: are consumers ready. Marketing Intelligence and Planning, 30(4), 418-443.

[45]. Persaud, A., \&Azhar, I. (2012). Innovative mobile marketing via smartphones: are

[46]. Peterson, L. and Low, B. (2011). Student attitudes towards mobile library services for smartphone. Journal of Library Hi Tech, 29(3), 412-23.

[47]. Prentice-Hall Inc., Englewood Cliffs, NJ.

[48]. Rao, S. and Troshani, I. (2007), "A conceptual framework and propositions for the acceptance of mobile services",Journal of Theoretical and Applied Electronic Commerce Research, Vol. 2 No. 2, pp. 61-73.

[49]. Rashotte, L. (2007). Social Influence. Retrieved from http://www.blackwellpub lishing.com 443/sociologt/docs/BEOS_S1413.pdf.

[50]. Rohm, A.J. and Swaminathan, V. (2004), "A typology of online shoppers based on shopping motivations",Journal of Business Research, Vol. 57, pp. 748-57.

[51]. Schiffman, L. G., Kanuk, L. L. and Wisenbut, J. (2009). Consumer Behavior, 10th ed., Pearson, Upper Saddle River, New Jersey.

[52]. Shoichi Morimoto and Kaori Nagahata, "Mapping Features of Smartphone on Consumer Behavior Model toward O2O2O" in The Seventh International Conference on Digital Society ICDS, 2013.

[53]. Sobel, M. E. (1987). Direct and indirect effects in linear structural equation models. Sociological Methods \& Research, 16(1), 155176.

[54]. Tauber, E.M. (1972), “Why do people shop?”,Journal of Marketing, Vol. 36 No. 4, pp. 46-9.

[55]. Theory and Research, Addison-Wesley, Reading, MA.

[56]. Vargo, S. L., Maglio, P. P. and Akaka, M. A. (2008). On value and value co-creation: A service systems and service logic perspective. European Management Journal, 26(3), 145-152.

[57]. Vargo, S. L., Maglio, P. P. and Akaka, M. A. (2008). On value and value co-creation: A service systems and service logic perspective. European Management Journal, 26(3), 145-152.

[58]. Vargo, S. L. and Lusch, R. F. (2004). Evolving to a New Dominant Logic for Marketing.

[59]. Venkatesh, V. \&Bala, H. (2008). Technology Acceptance Model 3 and a research agenda on interventions. Decision Sciences,39 (2), 273-315. 
[60]. Venkatesh, V. \& Davis, F. D. (2000). A theoretical extension of the technology acceptance model: Four longitudinal field studies. Management Science, 46(2), 186-204.

[61]. Venkatesh, V. \& Ramesh, V.(2002): Usability of Web and Wireless Sites : Extending the Appli c a bi li t y Of The Microsoft Usability Guidelines Instrument. Information Systems Technical Reports and Working Paper.

[62]. Venkatesh, V., Morris, M. G., Davis, G. B. \& Davis, F.D. (2003). User acceptance of information technology: Toward a unified view. MIS Quarterly, 27(3), 425-478

[63]. Venkatesh, V., Morris, M.G., Davis, G.B., Davis, F.D., (2003). User acceptance of information technology: toward a unified view. MIS Q. 27 (3), 425-478.

[64]. Vol. 79 No. 2, pp. 77-95

[65]. Wagner, J. (2011). Anytime/anywhere - playing catch up with the mind of the smartphone consumer. International Journal of Mobile Marketing, 6(1), 28-53

[66]. XuQian, and BellurSaraswathi (2010), "Designing Interactivity in Media Interfaces:

[67]. Yang, Z., Cai, S., Zhou, Z., Zhou, N., (2005). Development and validation of an instrument to measure user perceived service quality of information presenting web portals. Inform. Manage. 42 (4), 575-589. 